\title{
Localization of salt-tolerant QTL in rice germination stage under different salinity concentrations
}

\author{
Yanning Wang \\ Jiangxi Agricultural University \\ Guiting Song \\ Jiangxi Agricultural University \\ Liping Chen \\ Jiangxi Agricultural University \\ Tao Huang \\ Jiangxi Agricultural University \\ Guangliang Wu \\ Jiangxi Agricultural University \\ Jingai Tan \\ Jiangxi Agricultural University \\ Peng Wang \\ Jiangxi Agricultural University \\ Qin Cheng \\ Jiangxi Agricultural University \\ Caijing Li \\ Jiangxi Agricultural University \\ Qi Zhong \\ Jiangxi Agricultural University \\ Shiying Huang \\ Jiangxi Agricultural University \\ Mengmeng Yang \\ Jiangxi Agricultural University \\ Haohua He \\ Jiangxi Agricultural University \\ Jianmin Bian ( $\sim$ jmbian81@126.com ) \\ Jiangxi Agricultural University
}

\section{Research Article}

Keywords: rice, salt stress, root length, bud length, survival percent, QTL

Posted Date: February 8th, 2022

DOI: https://doi.org/10.21203/rs.3.rs-371410/v1

License: (c) (i) This work is licensed under a Creative Commons Attribution 4.0 International License. Read Full License 


\section{Abstract}

Salt stress is an important abiotic stress, which has seriously affected the reproductive development of rice in many parts of the world. Therefore, it is particularly important to understand the genetic mechanism of salt tolerance in rice. In this study, we preliminarily located some quantitative trait loci (QTL) for root length, bud length, and survival percent under different salinity conditions (0,100, 200 and $400 \mathrm{mM} \mathrm{NaCl})$, using a population of chromosome segment substitution lines (CSSLs) constructed by Nipponbare and 9311. A total of 20 QTLs were identified, which explained the phenotypic variation of $4.7636 \% \sim 37.5870 \%$. There are 7, 5 and 8 QTLs for root length, bud length and survival percent, respectively. And $q R L 1, q S P 2, q S P 3, q S P 4, q R L 5, q S P 7, q S P 7-$ 1, qSP9, qRL10, qRL10-1, qRL11, qRL11-2, qBL11, qBL11-1 and $q S P 12$ were reported for the first time. Under different salinity conditions, the QTLs located are different, that is to say, the salt tolerance mechanism of rice under different salinity conditions may be different. The specific genetic mechanism remains to be further verified. Those QTLs identified in the experiment may be valuable genetic factors for improving salt tolerance of rice. These QTLs can be used to improve salt tolerance of rice by molecular markers technology, which will help to further understand the genetic mechanism of salt tolerance of rice.

\section{Introduction}

Rice is the staple grain crop in the world, feeding half of the world's population (Lai et al. 2016; Pires et al. 2015; Shi et al. 2017). Salinization of land is a serious problem in agriculture, which is one of the major abiotic stress (Kumari et al. 2018). Due to unsustainable farming methods, poor irrigation methods (He et al. 2004; Li et al. 2019), sea level rise and improper use of fertilizers (Punyawaew et al. 2016; Yang and Guo 2018), most of the land and irrigated fields in the world are affected by salt stress (Pires et al. 2015), which severely affects the growth and development of crops (Shi et al. 2017). Rice is a glycophyte with different sensitivity to salt stress at different development stages (Rao et al. 2018; Wang et al. 2011). Salt stress has a serious effect on seed germination, seedlings and reproductive development in the rice (Ganie et al. 2019). Therefore, the breeding of salttolerant rice varieties is an important target for breeders and also an effective method to reduce salt stress damage in rice (Lekklar et al. 2019; Shi et al. 2017).

The previous research showed that the salt tolerance of rice was controlled by many genes (Lekklar et al. 2019), and the related traits of salt tolerance were complex (Li et al. 2019). Mining and utilizing salt-tolerant genes/QTL is not only beneficial to the cultivation of salt-tolerant rice ( $\mathrm{H}$. et al. 2004), but also have great significance for understanding the genetic mechanism of salt tolerance in rice (He et al. 2017; Wang et al. 2012). With the development of molecular marker technology, genetic mapping has become a powerful tool to identify QTL/genes that control important complex agronomic traits (Mardani et al. 2014; Pandit et al. 2010). In rice, many QTLs of salt tolerance have been identified by genetic map, most of which were located on chromosomes 1 , 2, 6 and 7, and a few are located on chromosomes 10 and 11 (Ammar et al. 2009; Zheng et al. 2015), but so far only a few salt tolerance genes have been cloned (Jahan et al. 2020). SKC1 is the first salt-tolerant gene successfully isolated by map-based cloning, which is located on chromosome 1 (Ren et al. 2005). SKC1 encodes a sodium transporter of HKT family (Li et al. 2017), which regulates $\mathrm{Na}^{+} / \mathrm{K}^{+}$homeostasis under salt stress (He et al. 2004). Another salt-tolerant gene, $D S T$, was obtained from salttolerant mutants by map-based cloning and located on chromosome 3 (Li et al. 2019). DST encodes a new zinc finger transcription factor, which negatively regulates the drought and salt tolerance of rice (Huang et al. 2009). HST1 is a newly identified salt-tolerant gene, which encodes a B-type response regulatory protein OsR22. HST1 may be involved as a transcription factor in regulating the expression of osmotic or ion transport related genes (Takagi et al. 2015). Although many QTLs for salt tolerance have been identified in rice, there are few studies on QTLs for salt tolerance under different salt concentrations (Wang et al. 2012), and the regulation mechanism of salt tolerance in rice under different salt stress is still unclear.

In this study, a set of chromosome segment substitution lines (CSSL), included 118 lines, derived from indica 9311 and japonica Nipponbare, were used to map and analyze the QTL for root length (RL), bud length (BL) and survival percent (SP) under different salinity concentrations at germination stage in rice. The aim of this study was to explore the genetic mechanism for salt stress tolerance in different salinity conditions and provide QTL for salt-tolerance rice varieties breeding by molecular-assisted selection (MAS) (Lai et al. 2016; Mardani et al. 2014).

\section{Materials And Methods}




\section{Plant materials}

A set of CSSL population, included 118 lines, derived from 9311 and Nipponbare. 9311, an indica variety, was used as the recipient parent; Nipponbare, an elite japonica variety, was used as the donor.

\section{Stress Treatment and evaluation}

Fourty filled and healthy seeds of parents and CSSLs were sterilized in 10\% sodium hypochlorite solution for 15 min and then rinsed with distilled water for three times (Mardani et al. 2014; Shi et al. 2017). The seeds were soaked in distilled water for 3 days to germinate (Li et al. 2017; Wang et al. 2012). Finally, 30 uniform germinated seeds were selected and placed in a petri dish with single-layer filter paper (Li et al. 2017). In the experimental group, the seeds were treated with $100 \mathrm{mM}, 200 \mathrm{mM}$ and $400 \mathrm{mM}$ sodium chloride solution. In the control group, the seeds were treated with distilled water. Each treatment has three replications (Wang et al. 2011). The treated seeds were cultured in an artificial climate chamber, maintaining a 14-hour light /10hour dark cycle $\left(27^{\circ} \mathrm{C} / 25^{\circ} \mathrm{C}\right)$ and $80 \%$ relative humidity (Wu et al. 2020 ; Shi et al. 2017). The solutions were replaced everyday ensure that the concentration of sodium chloride solution and the volume of distilled water remain unchanged (Mardani et al. 2014). The RL, BL and SP of each line were measured and collected on seventh day (Basu et al. 2017).

\section{Statistical analyses}

Statistical analysis and QTL mapping of CSSL population treated with different concentrations of sodium chloride were carried out by ICIMapping.4.2 software (Wang et al. 2012). The correlation analysis between RL, BL and SP were conducted by SPSS.statistics.22 software.

\section{Identification of QTL}

Taking RL, BL and SP under different concentrations of sodium chloride treatment as indicators, QTL mapping for salt tolerance in rice germination stage was carried out on CSSLs population by ICIMapping.4.2 software, and LOD > 2.5 was selected as threshold to determine whether QTL existed (Zheng et al. 2015). QTL nomenclature refers to the method proposed by McCouch (Lai et al. 2016; Wang et al. 2011).

\section{Results}

\section{Phenotypic variation of parents and CSSLs population}

The values of RL, BL and SP of parents and CSSLs population under different salinity conditions are shown in Table 1. There is a significant difference in RL between 9311 and Nipponbare under 0 and $100 \mathrm{mM} \mathrm{NaCl}$ conditions, and the length of 9311 is significantly higher than that of Nipponbare (Fig.1); There is a significant difference in BL between 9311 and Nipponbare under 0, 100 and $400 \mathrm{mM} \mathrm{NaCl}$ conditions, and the length of 9311 is significantly lower than that of Nipponbare (Fig.1). There was no significant difference in SP under different salt conditions. RL, BL and SP of CSSLs population showed continuous frequency distribution and transgressive segregation, which were consistent with the genetic characteristics of quantitative traits (Fig.2).

\section{Phenotypic correlation}

Pearson correlation coefficients of three salt-tolerant traits RL, BL and SP under different salinity conditions are shown in Table 2. $\mathrm{RL}, \mathrm{BL}$ and SP were significantly correlated at 200 and $400 \mathrm{mM} \mathrm{NaCl}(p<0.01)$, although there was no correlation between $\mathrm{RL}$ and $\mathrm{SP}$ at $200 \mathrm{mM} \mathrm{NaCl}$. There is no significant correlation between RL, BL and SP under control and $100 \mathrm{mM} \mathrm{NaCl}$, although there is a correlation between $\mathrm{RL}$ and $\mathrm{BL}$ under $100 \mathrm{mM} \mathrm{NaCl}(p<0.05)$.

\section{QTL analysis}

Under different salinity conditions, QTLs for three salt-tolerant traits are shown in Table 3, and the positions of these QTLs on chromosomes are shown in Fig.3.

\section{QTLs for root length}


Seven QTLs were detected for RL (Fig.3, Table 3). Under controlled condition, qRL1 and qRL 10-1 were located on chromosome 1 and 10 , with LOD values of 3.46 and 3.88 , which explained $10.41 \%$ and $11.96 \%$ of phenotypic variation, respectively. Under the $100 \mathrm{mM} \mathrm{NaCl}$ condition, $q R L 10$ was located on chromosome 10, with LOD value of 3.11 , which explained $11.43 \%$ of phenotypic variation. Under the $200 \mathrm{mM} \mathrm{NaCl}$ condition, QTLs $q R L 5, q R L 11, q R L 11-2$ were located on chromosome 5 and 10, with LOD values of $3.15,8.52$ and 4.36 , which explained the phenotypic variation of $4.76 \%-14.34 \%$. Under the $400 \mathrm{mM} \mathrm{NaCl}$ condition, $q R L 3$ was located on chromosome 3 , with LOD value of 5.70 , which explained $19.93 \%$ of phenotypic variation.

\section{QTLs for bud length}

Five QTLs were detected for BL (Fig.3, Table 3). Under controlled condition, $q B L 8$ and $q B L 11$ were located on chromosome 8 and 11 , with LOD values of 5.13 and 2.92 , which explained $15.84 \%$ and $8.63 \%$ of phenotypic variation, respectively. Under the $100 \mathrm{mM}$ $\mathrm{NaCl}$ condition, there was no QTL detected. Under the $200 \mathrm{mM} \mathrm{NaCl}$ condition, QTLs $q B L 8$ and $q B L 11-1$ were located on chromosome 8 and 11, with LOD values of 2.56 and 3.58, which explained the phenotypic variation of $7.99 \%$ and $11.41 \%$, respectively. Under the $400 \mathrm{mM} \mathrm{NaCl}$ condition, $q B L 3$ was located on chromosome 3, with LOD value of 3.43, which explained $12.51 \%$ of phenotypic variation.

\section{QTLs for survival percent}

Eight QTLs were detected for BL (Fig.3, Table 3). Under controlled condition, qSP2, qSP3 and qSP7-1 were located on chromosome 2,3 and 7, with LOD values of $3.69,4.31$ and 15.31 , which explained $7.07 \%, 8.46 \%$ and $37.59 \%$ of phenotypic variation, respectively. Under the $100 \mathrm{mM} \mathrm{NaCl}$ condition, $q S P 12$ was located on chromosome 12, with LOD value of 6.26, which explained $19.61 \%$ of phenotypic variation. Under the $200 \mathrm{mM} \mathrm{NaCl}$ condition, QTLs $q S P 7$ and $q S P 9$ were located on chromosome 7 and 9 , with LOD values of 6.64 and 2.54, which explained the phenotypic variation of $22.55 \%$ and $7.95 \%$, respectively. Under the $400 \mathrm{mM}$ $\mathrm{NaCl}$ condition, $q S P 3$ and $q S P 4$ was located on chromosome 3 and 4, with LOD value of 5.96 and 3.50, which explained 18.38\% and $10.28 \%$ of phenotypic variation.

\section{Candidate gene analysis}

Candidate genes were analyzed for QTLs with phenotypic variation over 10\%. There are 310 putative genes in $q R L 1, q S P 3, q S P 4$, qSP7-1, qRL 10, qRL11, qBL11-1 and qSP12. Among these candidate genes, homologous analysis showed that 16 genes were closely related to the previously cloned salt-tolerant genes (Lekklar et al. 2019) (Fig.4, Table 4), but these candidate genes need further verification.

\section{Discussion}

For breeders, it is a feasible way to cultivate salt-tolerant rice by aggregating salt-tolerant QTL/genes (Ganie et al. 2019). The detection of QTL is greatly promoted by using multiple related traits under different salinity stress (Wang et al. 2012). In order to reveal the genetic control of salt tolerance at rice germination stage, 20 salt-tolerant QTLs for three salt tolerance related indexes were identified on 12 chromosomes by using the newly constructed genetic map under different salinity conditions $(0,100,200$ and $400 \mathrm{mM} \mathrm{NaCl}$ ). Mining these salt-tolerant QTLs can greatly promote the process of rice salt-tolerant breeding.

In QTL analysis, $q S P 3$ and $q B L 8$ were located in Chr3-bin146 and Chr8-bin428, respectively (Fig. 3, Table 3). These QTLs are highly repetitive and have been detected under two different salinity conditions. Those QTLs with large phenotypic variation can be further studied. Although $q S P 3$ and $q B L 8$ were detected at different concentrations, the other eighteen QTLs were rarely colocated under different salt concentrations, that is to say, the mechanism of salt tolerance in rice at different concentrations may be different.

$q R L 3$ and $q B L 3$ controlling different traits were detected at the same position on the same chromosome, which may be related to the pleiotropy of QTLs, that is, QTLs of a certain segment on the chromosome act on multiple traits at the same time, which is common in rice (Ammar et al. 2009; H. et al. 2004). These QTL regions located in the same place are very useful for improving many traits at the same time (Lai et al. 2016). 
There have been many other reports on salt tolerance QTLs before (De Leon et al. 2016; Zheng et al. 2015). In this study, twenty QTLs were detected, including seven for RL, five for BL and eight for SP (Fig. 3, Table 3). By comparing the chromosome positions of these QTLs, we found that three QTLs in this study were close to the positions of several QTLs related to salt tolerance that have been mapped. For example, qBL8 located on chromosome 8 has the same chromosome interval as OsCPK21, which is involved in the positive regulation of abscisic acid and salt stress signal pathway (Asano et al. 2011). The $q S P 9$ on chromosome 9 has the same chromosome interval as OsRNS4 (Zheng et al. 2014). The $q R L 3$ located on chromosome 3 has the same chromosome interval as OsSUT1 and OsJAZ9. OsJAZ9 is involved in regulating potassium homeostasis, affecting $\mathrm{Na}^{+} / \mathrm{K}^{+}$ homeostasis and improving salt tolerance of rice (Siahpoosh et al. 2012; Wu et al. 2015). The $q R L 1, q S P 2, q S P 3, q S P 4, q R L 5$, qSP7, qSP7-1, qSP9, qRL10, qRL 10-1, qRL 11, qRL11-2, qBL11, qBL11-1 and qSP12 are different from the QTLs located before, suggesting that those QTLs may be new. These new salt-tolerant QTLs can be mapped finely by constructing secondary $F_{2}$ population, which greatly promotes the cloning of salt-tolerant genes. And the candidate genes predicted in this paper will also provide some reference for the cloning of salt-tolerant genes (Fig. 4, Table 4).

Most of the QTLs previously located are based on recombinant inbred lines or backcross inbred line population (Luo et al. 2020; Wang et al. 2012), and few of them use chromosome segment substitution lines. In this experiment, the population of CSSLs comprised of 118 line, and each line of CSSLs population is homozygous with good stability. As the background of most receptor parents in multi-generation backcross is gradually covered by recurrent parents, the interference of genetic background is eliminated, and the accuracy of QTL detection is improved (Bian et al. 2010). Therefore, CSSLs carrying QTLs detected in this experiment is an effective resource for improving salt tolerance of rice (Bian et al. 2010). These markers are closely linked with rice salt tolerance QTLs (H. et al. 2004), which will provide reference for rice salt tolerance breeding, contribute to the polymerization of rice salt tolerance QTLs, and realize high level of salt tolerance of rice.

\section{Declarations}

\section{Acknowledgment}

We thank the anonymous referees for their critical comments on this manuscript. This research was supported grants (20192ACBL20017; 20192BCB23010) from Project of Science and Technology Department of Jiangxi Province, grant (GJJ170241) from Project of Science and Technology Department of Department of Education of Jiangxi Province and grant (201910410003) from National Undergraduate Training Program for Innovation and Entrepreneurship.

\section{References}

1. Ammar MHM, Pandit A, Singh RK, Sameena S, Singh NK (2009) Mapping of QTLs Controlling $\mathrm{Na}^{+}, \mathrm{K}^{+}$and $\mathrm{Cl}^{-}$Ion Concentrations in Salt Tolerant Indica Rice Variety CSR27. Journal of Plant Biochemistry \& Biotechnology 18 (2)

2. Asano T, Hakata M, Nakamura H, Aoki N, Komatsu S, Ichikawa H, Hirochika H, Ohsugi R (2011) Functional characterisation of OsCPK21, a calcium-dependent protein kinase that confers salt tolerance in rice. Plant Mol Biol 75(1-2):179-191

3. Basu S, Giri RK, Benazir I, Kumar S, Rajwanshi R, Dwivedi SK, Kumar G (2017) Comprehensive physiological analyses and reactive oxygen species profiling in drought tolerant rice genotypes under salinity stress. Physiology and Molecular Biology of Plants

4. Bian JM, Jiang L, Liu LL, Wei XJ, Xiao YH, Zhang LJ, Zhao ZG, Zhai HQ, Wan JM (2010) Construction of a new set of rice chromosome segment substitution lines and identification of grain weight and related traits QTLs. Breed Sci 60(4):305-313

5. De Leon TB, Linscombe S, Subudhi PK (2016) Molecular Dissection of Seedling Salinity Tolerance in Rice (Oryza sativa L.) Using a High-Density GBS-Based SNP Linkage Map. Rice 9(1):52

6. Ganie SA, Molla KA, Henry RJ, Bhat KV, Mondal TK (2019) Advances in understanding salt tolerance in rice. Theoretical and Applied Genetics (130). https://doi.org/ 10.1007/s00122-019-03301-8

7. Lin HX, Zhu MZ, Yano M, J., and P (2004) QTLs for $\mathrm{Na}^{+}$and $\mathrm{K}^{+}$uptake of the shoots and roots controlling rice salt tolerance. Tag Theoretical \& Applied Genetics

Page 5/10 
8. He X, Li L, Xu H, Xi J, Xu Z (2017) A rice jacalin-related mannose-binding lectin gene, OsJRL, enhances Escherichia coli viability under high salinity stress and improves salinity tolerance of rice. Plant Biol 19(2):257

9. He Y, Yang B, He Y, Zhan C, Cheng Y, Zhang J, Zhang H, Cheng J, Wang Z. A quantitative trait locus, qSE3, promotes seed germination and seedling establishment under salinity stress in rice. Wiley-Blackwell Online Open 97 (6)

10. Huang XY, Chao DY, Gao JP, Zhu MZ, Shi M, Lin HX (2009) A previously unknown zinc finger protein, DST, regulates drought and salt tolerance in rice via stomatal aperture control. Genes Dev 23(15):1805-1817

11. Jahan N, Zhang Y, Lv Y, Song M, Guo L (2020) QTL analysis for rice salinity tolerance and fine mapping of a candidate locus qSL7for shoot length under salt stress. Plant Growth Regul 90 (1). https://doi.org/ 10.1007/s10725-019-00566-3

12. Kumari R, Kumar P, Sharma VK, Kumar H (2018) Seedling stage salt stress response specific characterization of genetic polymorphism and validation of SSR markers in rice. Physiology Molecular Biology of Plants 25 (2):1-13. https://doi.org/ 10.1007/s12298-018-0623-3

13. Lai Y, Cheng J, Wang, Zhoufei, Zhang H, He, and Yongqi (2016) Identification of QTLs with Additive, Epistatic, and QTL x Seed Maturity Interaction Effects for Seed Vigor in Rice. Plant molecular biology reporter

14. Lekklar C, Pongpanich M, Suriya-arunroj D, Chinpongpanich A, Tsai H, Comai L, Chadchawan S, Buaboocha T (2019) Genome-wide association study for salinity tolerance at the flowering stage in a panel of rice accessions from Thailand. BMC Genom 20 (1). https://doi.org/ 10.1186/s12864-018-5317-2

15. Li N, Sun J, Wang J, Liu H, Zheng H, Yang L, Liang Y, Li X, Zou D, Virk P (2017) QTL analysis for alkaline tolerance of rice and verification of a major QTL. Plant Breeding

16. Li N, Zheng H, Cui J, Wang J, Zou D (2019) Genome-wide association study and candidate gene analysis of alkalinity tolerance in japonica rice germplasm at the seedling stage. Rice 12 (1). https://doi.org/ 10.1186/s12284-019-0285-y

17. Luo X, Deng H, Wang P, Zhang X, Li C, Li C, Tan J, Wu G, Wang Y, Cheng Q, He H, Bian J (2020) Genetic analysis of germinating ability under alkaline and neutral salt stress by a high-density bin genetic map in rice. Euphytica 216 (7). https://doi.org/ 10.1007/s10681-020-02623-9

18. Mardani Z, Rabiei B, Sabouri H, Sabouri A (2014) Identification of molecular markers linked to salt-tolerant genes at germination stage of rice. Plant Breeding 133(2):196-202

19. Pandit A, Rai V, Bal S, Sinha S, Kumar V, Chauhan M, Gautam RK, Singh R, Sharma PC, Singh AK (2010) Combining QTL mapping and transcriptome profiling of bulked RILs for identification of functional polymorphism for salt tolerance genes in rice (Oryza sativa L.). Molecular Genetics Genomics 284(2):121-136

20. Pires IS, Negrao S, Oliveira MM, Purugganan MD (2015) Comprehensive phenotypic analysis of rice (Oryza sativa) response to salinity stress. Physiol Plant 155(1):43-54

21. Punyawaew K, Suriya-Arunroj D, Siangliw M, Thida M, Lanceras-Siangliw J, Fukai S, Toojinda T (2016) Thai jasmine rice cultivar KDML105 carrying Salto/ QTL exhibiting salinity tolerance at seedling stage. Mol Breeding 36(11):150

22. Rao PVR, John O, Kumar SP (2018) Identification of QTLs for Salt Tolerance Traits and Prebreeding Lines with Enhanced Salt Tolerance in an Introgression Line Population of Rice. Plant molecular biology reporter 36:695-709. https://doi.org/ 10.1007/s11105-018-1110-2

23. Ren ZH, Gao JP, Li LG, Cai XL, Huang W, Chao DY, Zhu MZ, Wang ZY, Luan S, and H. X. Lin. A rice quantitative trait locus for salt tolerance encodes a sodium transporter. Nature Genetics. https://doi.org/ 10.1038/ng1643

24. Shi Y, Gao L, Wu Z, Zhang X, Wang M, Zhang C, Zhang F, Zhou Y, Li Z (2017) Genome-wide association study of salt tolerance at the seed germination stage in rice. BMC Plant Biol 17(1):92

25. Siahpoosh MR, Sanchez DH, Schlereth A, Scofield GN, Furbank RT, van Dongen JT, Kopka J (2012) Modification of OsSUT1 gene expression modulates the salt response of rice Oryza sativa cv. Taipei 309. Plant Sci 182:101-111

26. Takagi H, Tamiru M, Abe A, Yoshida K, Uemura A, Yaegashi H, Obara T, Oikawa K, Utsushi H, Kanzaki E, Mitsuoka C, Natsume S, Kosugi S, Kanzaki H, Matsumura H, Urasaki N, Kamoun S, Terauchi R (2015) MutMap accelerates breeding of a salttolerant rice cultivar. Nat Biotechnol 33(5):445-449

27. Wang Z, Cheng J, Chen Z, Huang J, Bao Y, Wang J, Zhang H (2012) Identification of QTLs with main, epistatic and QTL × environment interaction effects for salt tolerance in rice seedlings under different salinity conditions. Theor Appl Genet 
125(4):807-815

28. Wang Z, Wang J, Bao Y, Wu Y, Zhang H (2011) Quantitative trait loci controlling rice seed germination under salt stress. Euphytica 178(3):297-307

29. Wu G, Deng H, Yu M, Cai Y, Zhou D, Tan J, Yu J, Luo X, Tong S, Wang P, Zhang X, Li C, Li C, Wang Y, Cheng Q, He H, Bian J (2020) Genetic analysis of rice seed recovery under low-temperature conditions using a new CSSL population with a highdensity genetic map in rice. Mol Breeding 40:(12)

30. Wu H, Ye H, Yao R, Zhang T, Xiong L (2015) OsJAZ9 acts as a transcriptional regulator in jasmonate signaling and modulates salt stress tolerance in rice. Plant Sci 232:1-12

31. Yang Y, Guo Y (2018) Unraveling salt stress signaling in plants. J Integr Plant Biol 60(09):58-66

32. Zheng H, Zhao H, Liu H, Wang J, Zou D (2015) QTL analysis of $\mathrm{Na}^{+}$and $\mathrm{K}^{+}$concentrations in shoots and roots under $\mathrm{NaCl}$ stress based on linkage and association analysis in japonica rice. Euphytica 201(1):109-121

33. Zheng J, Wang Y, He Y, Zhou J, Li Y, Liu Q, Xie X (2014) Overexpression of an S-like ribonuclease gene, OsRNS4, confers enhanced tolerance to high salinity and hyposensitivity to phytochrome-mediated light signals in rice. Plant Sci 214:99-105

\section{Tables}

Table 1 Phenotypic values of parents and CSSLs under different salt stress

\begin{tabular}{|c|c|c|c|c|c|c|c|}
\hline \multirow[t]{2}{*}{ Treatments } & \multirow[t]{2}{*}{ Indices } & \multicolumn{2}{|c|}{ Parents } & \multicolumn{4}{|c|}{ CSSLS } \\
\hline & & 9311 & Nipponbare & Min & Max & Mean & Variance \\
\hline \multirow[t]{3}{*}{ Water $₫$ control $\bigotimes$} & $\mathrm{RL}$ & 4.86 & 3.43 & 3.47 & 7.12 & 5.69 & 0.48 \\
\hline & $\mathrm{BL}$ & 4.37 & 3.84 & 3.41 & 5.45 & 4.60 & 0.19 \\
\hline & SP & 1.00 & 1.00 & 0.92 & 1.00 & 0.99 & 0.00 \\
\hline \multirow[t]{3}{*}{$100 \mathrm{mM} \mathrm{NaCl}$} & $\mathrm{RL}$ & 2.27 & 1.54 & 0.61 & 2.12 & 1.30 & 0.11 \\
\hline & $\mathrm{BL}$ & 3.09 & 2.69 & 1.45 & 3.70 & 2.83 & 0.13 \\
\hline & SP & 1.00 & 1.00 & 0.88 & 1.00 & 0.99 & 0.00 \\
\hline \multirow[t]{3}{*}{$200 \mathrm{mM} \mathrm{NaCl}$} & $\mathrm{RL}$ & 0.89 & 0.76 & 0.18 & 1.37 & 0.49 & 0.03 \\
\hline & $\mathrm{BL}$ & 1.57 & 1.60 & 1.06 & 2.41 & 1.75 & 0.08 \\
\hline & $\mathrm{SP}$ & 1.00 & 0.99 & 0.70 & 1.00 & 0.95 & 0.00 \\
\hline \multirow[t]{3}{*}{$400 \mathrm{mM} \mathrm{NaCl}$} & $\mathrm{RL}$ & 0.00 & 0.00 & 0.00 & 0.24 & 0.04 & 0.00 \\
\hline & $\mathrm{BL}$ & 0.45 & 0.75 & 0.00 & 1.11 & 0.24 & 0.05 \\
\hline & SP & 0.94 & 0.94 & 0.00 & 1.00 & 0.13 & 0.02 \\
\hline
\end{tabular}

$\mathrm{RL}$ root length, $\mathrm{BL}$ bud length, SP survival percent

Table 2 The correlation of tolerance indices under different salt stress

\begin{tabular}{|c|c|c|c|c|c|c|c|c|c|c|c|c|}
\hline \multirow[t]{2}{*}{ Traits } & \multicolumn{3}{|c|}{ Water $\$ control $\rrbracket$} & \multicolumn{3}{|c|}{$100 \mathrm{mM} \mathrm{NaCl}$} & \multicolumn{3}{|c|}{$200 \mathrm{mM} \mathrm{NaCl}$} & \multicolumn{3}{|c|}{$400 \mathrm{mM} \mathrm{NaCl}$} \\
\hline & $\mathrm{RL}$ & $\mathrm{BL}$ & SP & $\mathrm{RL}$ & $\mathrm{BL}$ & SP & $\mathrm{RL}$ & $\mathrm{BL}$ & SP & $\mathrm{RL}$ & $\mathrm{BL}$ & SP \\
\hline $\mathrm{RL}$ & 1 & & & 1 & & & 1 & & & 1 & & \\
\hline$B L$ & 0.175 & 1 & & $0.190 *$ & 1 & & 0.370 ** & 1 & & 0.760 ** & 1 & \\
\hline SP & -0.103 & -0.013 & 1 & -0.063 & -0.138 & 1 & -0.046 & $0.324^{\star *}$ & 1 & $0.518^{* *}$ & $0.575^{\star \star}$ & 1 \\
\hline
\end{tabular}

** Correlation is significant at the 0.01 level; * Correlation is significant at the 0.05 level. 
$\mathrm{RL}$ root length, $\mathrm{BL}$ bud length, SP survival percent

Table 3 The QTLs for salt tolerance indices under different salt stress

\begin{tabular}{|c|c|c|c|c|c|c|c|}
\hline Treatment & Indices & QTL & $\mathrm{Chr}$ & Marker & LOD & Add & PVE(\%) \\
\hline \multirow[t]{7}{*}{ 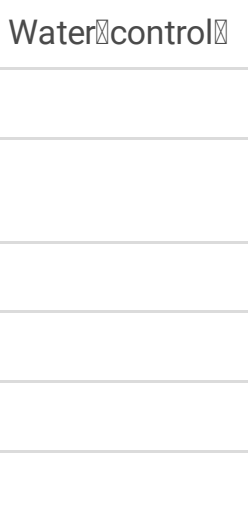 } & $\mathrm{RL}$ & $q R L 1$ & 1 & chr1-bin5 & 3.46 & -0.56 & 10.41 \\
\hline & & $q R L 10-1$ & 10 & Chr10-bin508 & 3.88 & -0.65 & 11.96 \\
\hline & $\mathrm{BL}$ & $q B L 8$ & 8 & Chr8-bin428 & 5.13 & -0.48 & 15.84 \\
\hline & & $q B L 11$ & 11 & Chr11-bin544 & 2.92 & -0.23 & 8.63 \\
\hline & SP & $q S P 2$ & 2 & Chr2-bin127 & 3.69 & -0.01 & 7.07 \\
\hline & & qSP3 & 3 & Chr3-bin146 & 4.31 & -0.02 & 8.46 \\
\hline & & $q S P 7-1$ & 7 & Chr7-bin378 & 15.36 & -0.04 & 37.59 \\
\hline \multirow[t]{2}{*}{$100 \mathrm{mM} \mathrm{NaCl}$} & $\mathrm{RL}$ & $q R L 10$ & 10 & Chr10-bin501 & 3.11 & -0.21 & 11.43 \\
\hline & SP & $q S P 12$ & 12 & Chr12-bin600 & 6.26 & -0.05 & 19.61 \\
\hline \multirow[t]{7}{*}{$200 \mathrm{mM} \mathrm{NaCl}$} & $\mathrm{RL}$ & qRL5 & 5 & Chr5-bin295 & 3.16 & 0.28 & 4.76 \\
\hline & & $q R L 11$ & 11 & Chr11-bin593 & 8.52 & 0.17 & 14.34 \\
\hline & & $q R L 11-1$ & 11 & Chr11-bin596 & 4.36 & -0.14 & 6.74 \\
\hline & $\mathrm{BL}$ & $q B L 8$ & 8 & Chr8-bin428 & 2.56 & -0.23 & 7.99 \\
\hline & & $q B L 11-1$ & 11 & Chr11-bin546 & 3.58 & -0.18 & 11.41 \\
\hline & SP & $q S P 7$ & 7 & Chr7-bin370 & 6.64 & -0.05 & 22.55 \\
\hline & & $q S P 9$ & 9 & Chr9-bin463 & 2.54 & -0.04 & 7.95 \\
\hline \multirow[t]{4}{*}{$400 \mathrm{mM} \mathrm{NaCl}$} & $\mathrm{RL}$ & $q R L 3$ & 3 & Chr3-bin139 & 3.70 & 0.06 & 19.93 \\
\hline & $\mathrm{BL}$ & $q B L 3$ & 3 & Chr3-bin139 & 3.43 & 0.22 & 12.51 \\
\hline & SP & $q S P 3$ & 3 & Chr3-bin146 & 5.96 & 0.37 & 18.38 \\
\hline & & $q S P 4$ & 4 & Chr4-bin211 & 3.50 & 0.14 & 10.28 \\
\hline
\end{tabular}

$\mathrm{RL}$ root length, $\mathrm{BL}$ bud length, SP survival percent

Table 4 Candidate genes related to salt stress 


\begin{tabular}{|c|c|c|c|}
\hline QTL & Putative genes & Gene name or Annotation & Reference genes \\
\hline \multirow[t]{5}{*}{$q R L 1$} & LOC_Os01g03320 & BBTI2 - Bowman-Birk type bran trypsin inhibitor precursor & OsCam1-1 \\
\hline & LOC_Os01g03180 & Retrotransposon protein & OsJAZ9; OsTIFY11a \\
\hline & LOC_Os01g03210 & None & OsHKT1; 5 OsHKT2; 4 \\
\hline & LOC_Os01g03452 & Transposon protein & OsHKT2; 1 \\
\hline & LOC_Os01g03464 & None & OsHKT1; 4 \\
\hline \multirow[t]{2}{*}{ qSP3 } & LOC_Os03g21480 & HAD superfamily phosphatase & OsSUT1 \\
\hline & LOC_Os03g21340 & Retrotransposon protein & RSS3 \\
\hline \multirow[t]{2}{*}{$q S P 7-1$} & LOC_Os07g35050 & OsFBX237 - F-box domain containing protein & OsCam1-1 \\
\hline & LOC_Os07g35070 & OsFBX239 - F-box domain containing protein & OsHKT2; 1 \\
\hline \multirow[t]{3}{*}{ qRL 10} & LOC_Os10g26180 & None & OsHAK21; qSE3 \\
\hline & LOC_Os10g26030 & Retrotransposon protein & SRWD4 \\
\hline & LOC_Os10g25940 & Conserved hypothetical protein & RSS2; OsPDR12 \\
\hline \multirow[t]{2}{*}{$q B L 11-1$} & LOC_Os11g11510 & 3-5 exonuclease domain-containing protein & OsCPK21 \\
\hline & LOC_Os11g11350 & Embryogenesis transmembrane protein & OsHAK1 \\
\hline qSP12 & LOC_Os12g02180 & None & DST \\
\hline
\end{tabular}

\section{Figures}

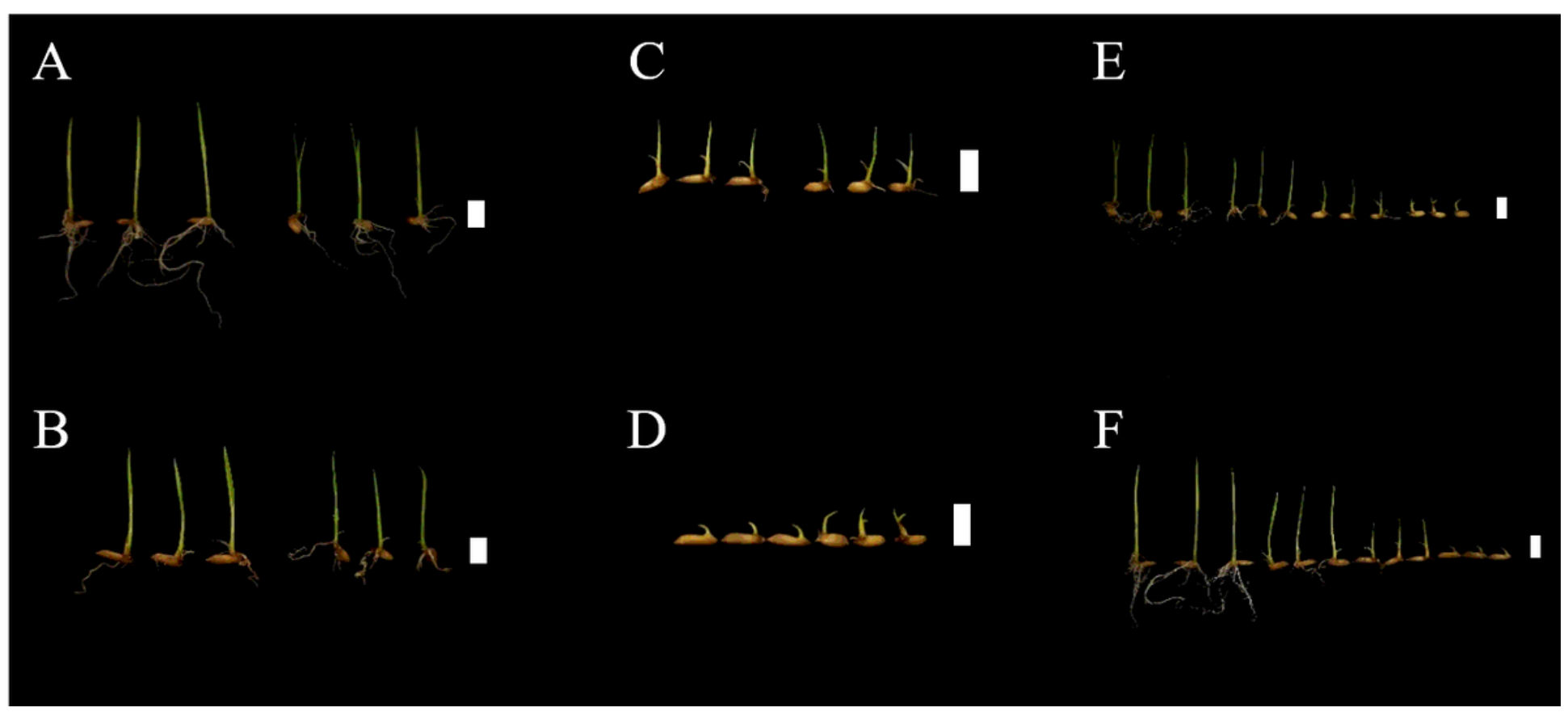

Figure 1

The situation of Nippobare and 9311 under different salt stress.

(A) The situation of 9311 (left) and Nippobare (right) under control condition; (B) The situation of 9311 and Nippobare under 100 $\mathrm{mM} \mathrm{NaCl}$ (C) The situation of 9311 and Nippobare under $200 \mathrm{mM} \mathrm{NaCl}$; (D) The situation of 9311 and Nippobare under $400 \mathrm{mM}$ $\mathrm{NaCl}$; (E) The situation of Nippobare under different salt stress; (F) The situation of 9311 under different salt stres. $S c a l e: 0.5 \mathrm{~cm}$. 
Figure 2

Frequency Distribution Histogram of RL, BL and SP in CSSLs population under different salt stress.

\section{Figure 3}

Position of QTL for RL, BL and SP in CSSLs population under different salt stress.

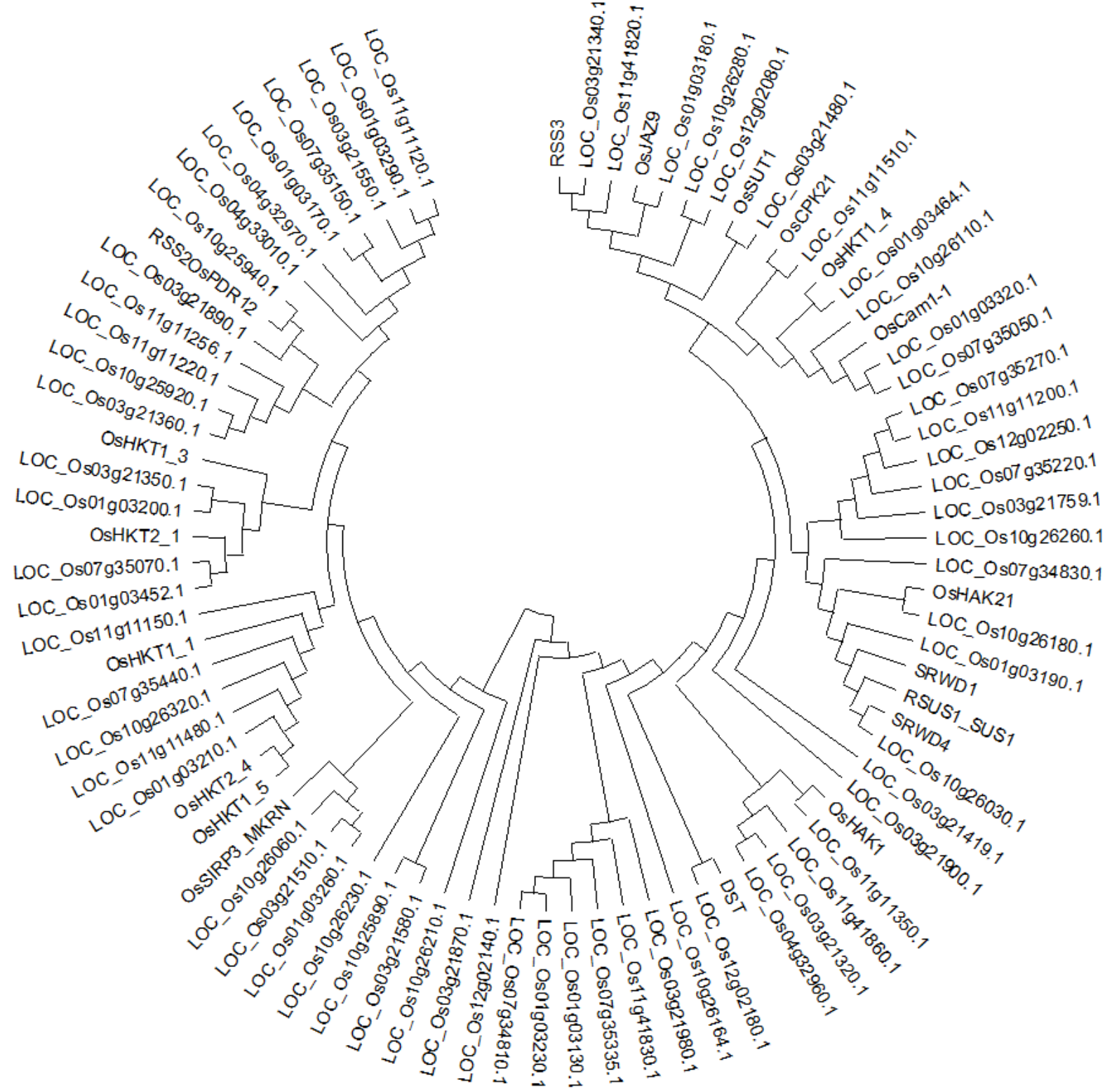

Figure 4

Evolutionary tree of candidate genes and salt tolerance related genes. 